Canadian

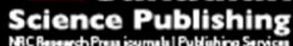

Applied Physiology, Nutrition, and Metabolism Physiologie appliquée, nutrition et métabolisme

\title{
Physiological responses during intermittent running exercise differ between outdoor and treadmill running
}

\begin{tabular}{|r|l|}
\hline Journal: & Applied Physiology, Nutrition, and Metabolism \\
\hline Manuscript ID & apnm-2017-0132.R2 \\
\hline Manuscript Type: & Article \\
\hline Date Submitted by the Author: & 17-May-2017 \\
\hline Complete List of Authors: & $\begin{array}{l}\text { Panasci, Marco; Universita degli Studi di Milano, School of Sport Science } \\
\text { Lepers, Romuald; Université Bourgogne Franche-Comté, Faculty of Sport } \\
\text { Sciences } \\
\text { La Torre, Antonio; Universita degli Studi di Milano, Department of } \\
\text { Biomedical Sciences for Health } \\
\text { Bonato, Matteo; Università degli Studi di Milano, Milan, Italy, Department } \\
\text { of Biomedical Sciences for Health } \\
\text { Assadi, Hervè; Université Bourgogne Franche-Comté, Faculty of Sport } \\
\text { Sciences }\end{array}$ \\
\hline $\begin{array}{r}\text { Is the invited manuscript for } \\
\text { consideration in a Special } \\
\text { Issue? : }\end{array}$ & $\begin{array}{l}\text { Keyword: } \\
\text { Knterval Training, Athletic Track, Motorized Treadmill, Oxygen Uptake }\end{array}$ \\
\hline \multicolumn{2}{|c|}{}
\end{tabular}


Title. Physiological responses during intermittent running exercise differ between outdoor and treadmill running

\section{Authors}

Panascì Marco ${ }^{1}$, Lepers Romuald $^{2}$, La Torre Antonio $^{3}$, Bonato Matteo $^{3}$, Assadi Hervè $^{2}$

\section{Institutional Affiliations:}

1. School of Sport Science, Università degli Studi di Milano, Milan, Italy

2. CAPS INSERM U1093, Faculty of Sport Sciences, Université Bourgogne FrancheComté, Dijon, France

3. Department of Biomedical Sciences for Health, Università degli Studi di Milano, Milan, Italy.

\section{Corresponding Author:}

Matteo Bonato, Ph.D.

Department of Biomedical Sciences for Health, Università degli Studi di Milano, Milan, Italy, Via Giuseppe Colombo 71, 20133 Milano, Italy

Phone: $+39-02-50314658$

Fax: +39-02-5031 463

E-Mail: matteo.bonato@unimi.it 


\section{Abstract}

The aim of this study was to compare the physiological responses during $15 \mathrm{~min}$ of intermittent running consisting of $30 \mathrm{~s}$ high intensity running exercise at maximal aerobic velocity (MAV) interspersed with $30 \mathrm{~s}$ passive recovery (30-30) performed outdoor versus on a motorized treadmill. Fifteen collegiate physically active males (age: $22 \pm 1$ years-old; body mass: $66 \pm 7 \mathrm{~kg}$; stature: $176 \pm 06 \mathrm{~cm}$, weekly training volume: $5 \pm 2 \mathrm{~h} \cdot \mathrm{week}^{-1}$ ), performed Fitness Intermittent test $45-15$ in order to determine $\dot{V} \mathrm{O}_{2 \max }$ and Maximal Aerobic Velocity (MAV) and then completed in random order three different training sessions consisting of 30s run -30 s rest outdoor on athletic track (30-30 Track) at MAV; 30s run -30s rest on treadmill (30-30 Treadmill) at MAV; 30s run -30 s rest at MAV+15\% (30-30+15\% MAV Treadmill). $\dot{V} \mathrm{O}_{2}$, time above $90 \% \dot{V} \mathrm{O}_{2 \max }\left(\mathrm{t} 90 \% \dot{V} \mathrm{O}_{2 \max }\right)$, Rating of Perceived Exertion (RPE), were measured during each training session. We observed a statistical significant underestimation of $\dot{V} \mathrm{O}_{2}\left(53.1 \pm 5.4 \mathrm{ml} \cdot \mathrm{kg}^{-1} \cdot \mathrm{min}^{-1}\right.$ vs $\left.49.8 \pm 6.7 \mathrm{ml} \cdot \mathrm{kg}^{-1} \cdot \mathrm{min}^{-1},-6.3 \%, \mathrm{P}=0.012\right), \mathrm{t} 90 \% \dot{V} \mathrm{O}_{2 \max }$ $(8.6 \pm 11.5 \%$ vs $38.7 \pm 32.5 \%,-77.8 \%, \mathrm{P}=0.008), \mathrm{RPE}(11.4 \pm 1.4$ vs $16.5 \pm 1.7,-31 \%, \mathrm{P}<$ 0.0001) during the 30-30 Treadmill compared to the same training session performed on track. No statistical differences between 30-30+15\% MAV Treadmill and 30-30 Track were observed. The present study demonstrates that an $15 \%$ increase in running velocity during a high intermittent intensity treadmill training session is the optimal solution to reach the same physiological responses than an outdoor training session.

Keywords: Interval Training, Athletic Track, Motorized Treadmill, Oxygen Uptake. 


\section{Résumé}

Le but de cette étude était de comparer les réponses physiologiques durant 15 min d'exercices intermittents $30 \mathrm{~s}-30$ s réalisés sur piste et sur tapis roulant, constitué de $30 \mathrm{~s}$ de course à la vitesse maximale aérobie (VMA) et 30s de récupération passive. Quinze sujets masculins sportifs (âge $22 \pm 1$ ans ; poids: $66 \pm 7 \mathrm{~kg}$; taille: $176 \pm 06 \mathrm{~cm}$ et un volume d'entrainement: $5 \pm 2$ $\mathrm{h} \cdot$ semaine $^{-1}$ ) ont effectués à une semaine d'intervalle le Fitness Intermittent Test 45-15 afin de déterminer le $\dot{V} \mathrm{O}_{2 \max }$ et la vitesse maximale aérobie plus 3 différentes sessions d'entrainement d'exercice 30s-30s constitué de: 30s-30s sur piste (30-30 Piste) à la VMA; 30s-30s sur tapis roulant (30-30 TR) à la VMA; 30s -30 s sur tapis roulant à la VMA $+15 \%$ (30-30+15\% VMA TR). Au cours de ces exercices, la consommation maximale d'oxygène $\left(\dot{V} \mathrm{O}_{2 \max }\right)$, le tlim $90 \% \dot{V} \mathrm{O}_{2 \max }\left(\mathrm{t} 90 \% \dot{V} \mathrm{O}_{2 \max }\right)$ et leperception de l'effort (RPE), ont été mesurées durant chaque session d'exercice. Il y'a une significative sous-estimation du $\dot{V} \mathrm{O}_{2}$ $\left(53.1 \pm 5.4 \mathrm{ml} \cdot \mathrm{kg}^{-1} \cdot \mathrm{min}^{-1}\right.$ vs $\left.49.8 \pm 6.7 \mathrm{ml} \cdot \mathrm{kg}^{-1} \cdot \mathrm{min}^{-1},-6.3 \%, \mathrm{P}=0.012\right), \mathrm{t} 90 \% \dot{V} \mathrm{O}_{2 \max }(8.6 \pm$ $11.5 \%$ vs $38.7 \pm 32.5 \%,-77.8 \%, \mathrm{P}=0.008), \mathrm{RPE}(11.4 \pm 1.4$ vs $16.5 \pm 1.7,-31 \%, \mathrm{P}<0.0001)$ durant l'exercice intermittent 30-30 sur tapis roulant comparé à la même séance d'entrainement sut piste. Il n'y a pas de différence significative entre l'exercice intermittent 30-30+15\% VMA Tapis roulant et 30-30 sur piste. Nous pouvons conclure que l'augmentation de $15 \%$ de la vitesse de course durant un exercice intermittent sur Tapis roulant è une bonne solution pour obtenir une sollicitation énergétique comparable à celle réalisé sur piste.

Mots-clés: entraînement par intervalles; piste d'athlétisme; tapis roulant; consommation maximale d'oxygène. 


\section{Introduction}

Over the last decades, there has been a growing interest in high intensity training (HIT) (Buchheit and Laursen 2013a, 2013b; Laursen and Jenkins 2002). HIT can be broadly defined as repeated bouts of short to moderate duration exercise (i.e. 10 seconds to 5 minutes) completed at an intensity that is greater than the anaerobic threshold (Laursen and Jenkins 2002). Exercise bouts are separated by brief periods of low-intensity work or inactivity that allow a partial but often not a full recovery. The purpose of HIT is to repeatedly stress the physiological systems that will be used during a specific endurance-type exercise (Daniels and Scardina 1984) to a greater extent than that which is actually required during the activity. It has been clearly demonstrated that HIT in both recreational and elite athletes can lead improvement in performance due to both central and peripheral adaptations (Laursen and Jenkins 2002).

Buchheit and Laursen (2013a) defined the intermittent exercise as a HIT in which the work duration is lower that $60 \mathrm{~s}$ in which the physiological strain is elicited essentially using a large requirement from the oxygen transport and utilisation system also with an anaerobic glycolytic energy contribution. In particular, the intermittent exercise consisted of $30 \mathrm{~s}$ work interspersed with $30 \mathrm{~s}$ rest (30-30) is frequently used in endurance sports to develop performance (Billat et al. 2000; Tardieu-Berger et al. 2004; Thevenet et al. 2007). Moreover, it allows athletes to maintain a greater work intensities for longer durations (Åstrand et al. 1960; Billat et al. 2000; Demarie et al. 2000; Millet et al. 2003a, 2003b; Tardieu-Berger et al. 2004; Midgley et al. 2007; Thevenet et al. 2007), and longitudinal studies have demonstrated its effectiveness in improving oxygen uptake (Burke et al. 1994; Gorostiaga et al. 1991; Overend et al. 1992). It has been demonstrated that the running velocity sustained during an 
intermittent exercise has a significant effect on oxygen uptake (Karlsson et al. 1967) and that the increase in maximal oxygen uptake depends on the work intensity rather than the duration of training (Fox et al. 1973, 1975).

HIT running exercise can be performed either in outdoor conditions or on motorized treadmill. According to Schache et al. (2001) the treadmill present an environment where variables such as velocity and gradient can be standardized and reproduced. However, the studies of Nigg et al. (1995) and Sinclair et al (2013), clearly demonstrated that the differences between treadmill and outdoor running can be subdivided into systematic and subject dependent components. According to Nigg et al. (1995) the subject systematically adapts his landing style on treadmill so that the foot could land in a flatter position in order to be more stable and for this reason the use of treadmill can both over predict and under predict aspects of ankle joint kinematics. In addition, Sinclair et al. (2013) concluded that treadmill running is associated with a significantly greater peak ankle eversion. These have potential consequences on thermoregulation, energy cost of overcoming air resistance and energy to accelerate at the beginning of the run. Furthermore, there is no air resistance during treadmill running, and for this reason slight inclinations of treadmill are generally used (Heck et al. 1985; Tegtbur et al. 1993; Jones and Doust 1996). In particular, Jones and Doust (1996), demonstrated that the energetic cost of treadmill running with the use of a $1 \%$ treadmill grade over a duration of $5 \mathrm{~min}$ and at velocities between 2.92 and $5.0 \mathrm{~m} \cdot \mathrm{s}^{-1}$ was similar to an outdoor running.

In this context, the main aim of this study was to compare the physiological responses reached during a 15 min of HIT running exercise performed at the same velocity outdoor on a track versus on a motorized treadmill at $1 \%$ of grade. 


\section{Material and Methods}

\section{Subjects}

Fifteen collegiate males (age $22 \pm 1$ years-old; body mass $66 \pm 7 \mathrm{~kg}$; stature $176 \pm 06 \mathrm{~cm}$, weekly training volume: $5 \pm 2$ hours per week) volunteered to participate in the study. Before entering the study, the participants were fully informed about the study aims and procedures, and they provided written informed consent before testing. Subjects were instructed to arrive in a rested and fully hydrated state and at least $3 \mathrm{~h}$ after the last meal and to avoid strenuous exercise in the $24 \mathrm{~h}$ preceding each test session. In addition, they were asked to refrain from caffeine and alcohol $24 \mathrm{~h}$ before the test. All tests were performed at the same time of the day $( \pm 1 \mathrm{~h})$ to avoid influence of circadian rhythms. The subjects were physically active and familiarized with aerobic activities such as running, cycling or soccer. Because subjects had no experienced in intermittent running exercises on treadmill, they were fully familiarized with all exercise testing procedures. All subjects completed the testing and training sessions without complication and it was generally well tolerated and subjects did not report dizziness, light-headiness of nausea, symptoms that occasionally occur during this type of test. A local ethics committee for the protection of individuals gave approval concerning the project before its initiation and conducted in accordance with current national and international laws and regulations governing the use of human subjects (Declaration of Helsinki II). Written informed consent was obtained before testing.

\section{Anthropometric assessment}

The anthropometric assessment was performed during baseline assessment. Barefoot subjects' stature to the nearest $0.5 \mathrm{~cm}$ and body mass of subjects in their underwear to the nearest 0.1 kg was measured (Seca 217, Vogel \& Halke, Hamburg Germany). 


\section{Maximal oxygen uptake and Maximal Aerobic Velocity assessment}

Oxygen Consumption $\left(\dot{V} \mathrm{O}_{2}\right)$, Respiratory Exchange Ratio (RER), were measured on a breathby-breath basis by a portable telemetric metabolimeter $\left(\mathrm{K} 4 \mathrm{~b}^{2}\right.$ Cosmed, Rome Italy; Mc Laughlin et al. 2001) during the Fitness Intermittent test 45-15 (FIT 45-15) that is an accurate field test that has been shown to be reliable to determine $\dot{V} \mathrm{O}_{2 \max }$ and Maximal Aerobic Velocity (MAV) (Assadi \& Lepers 2012). This protocol consisted of periods of 45 s run on a field interspersed with periods of $15 \mathrm{~s}$ recovery. During the first $45 \mathrm{~s}$, the subject had to run a distance of $125 \mathrm{~m}$ from the "Start 1 " cone to the "Finish 1 " cone (mean velocity $10 \mathrm{~km} \cdot \mathrm{h}^{-1}$ ). During the following $15 \mathrm{~s}$ rest, the subject had to move from the "Finish 1" cone to the "Start 2" cone, located $6.25 \mathrm{~m}$ away. The next $45 \mathrm{~s}$ runs with a speed increase of $0.5 \mathrm{~km} \cdot \mathrm{h}^{-1}$, in fact the subject runs $131.25 \mathrm{~m}\left(10.5 \mathrm{~km} \cdot \mathrm{h}^{-1}\right)$. After $15 \mathrm{~s}$ recovery, he had to run from the "Start 3" cone to the "Finish 3" cone he had to run $137.50 \mathrm{~m}$ in $45 \mathrm{~s}$ (mean velocity $11.0 \mathrm{~km} \cdot \mathrm{h}^{-1}$ ). Starts and stops were announced by a sound signal emitted by a beep generator. At every stage the distance increased by $6.25 \mathrm{~m}$ (i.e., the velocity increases by $0.5 \mathrm{~km} \cdot \mathrm{h}^{-1}$ ). The test was stopped when the subject, for two consecutive times, was not able to reach a desired cone in the corresponding time. The last velocity reached during the test was considered the MAV. $\dot{V} \mathrm{O}_{2 \max }$ was estimated according to the criterion described by Thevenet et al. (2007). Heart Rate (HR) was recorded during the whole test by a HR monitor (S610i, Polar Electro, Kempele, Finland). All testing session were conducted outdoor on an athletic track in dry, windless weather conditions.

\section{Training sessions}

Subjects were invited to perform in random order these different training sessions: 1) 15 min of intermittent running on an athletic track consisting of $30 \mathrm{~s}$ high intensity running at MAV interspersed with 30 s passive recovery (30-30 Track); 2) 15 min of intermittent running on 
treadmill consisting of $30 \mathrm{~s}$ high intensity running at MAV interspersed with $30 \mathrm{~s}$ passive recovery (30-30 Treadmill); 15 min of intermittent running on treadmill consisting of $30 \mathrm{~s}$ high intensity running at $\mathrm{MAV}+15 \%$ with $30 \mathrm{~s}$ passive recovery $(30-30+15 \% \mathrm{MAV}$ Treadmill). The choice to increase the velocity by $15 \%$ has been defined after preliminary tests. For the treadmill training session, the velocity of belt was maintained also during the 30 s of recovery. In fact, subjects have to stand up with the feet on each side on the treadmill and during the $30 \mathrm{~s}$ of high intensity running have to move instantaneously on the treadmill and run at the given velocity. 30-30 Track was conducted outdoor on an athletic track in dry, windless weather conditions, whereas 30-30 Treadmill and 30-30 + 15\% MAV Treadmill were performed in laboratory. Outdoor running was only performed if the wind speed was less than $2.0 \mathrm{~m} \cdot \mathrm{s}^{-1}$; usually during outdoor running test wind speed was much less than this and averaged $1.2 \pm 0.4 \mathrm{~m} \cdot \mathrm{s}^{-1}$. The laboratory and outside temperatures were similar and ranged between $14^{\circ}$ and $18^{\circ} \mathrm{C}$ All laboratory training sessions were carried out on a motorized treadmill (J Ergo-Fit Trac 3000 Alpin, Germany) set at a 1\% gradient (Jones and Doust, 1996). During each training session $\dot{V} \mathrm{O}_{2}, \dot{V} \mathrm{CO}_{2}, \mathrm{RER}$ and $\dot{V} \mathrm{E}$ were measured on a breath-by-breath basis by a portable telemetric metabolimeter ( $\mathrm{K} 4 \mathrm{~b}^{2}$ Cosmed, Rome Italy). Moreover, we considered $\mathrm{t} 90 \% \dot{\mathrm{V}} \mathrm{O}_{2 \max }$ as the time spent above $90 \% \dot{V} \mathrm{O}_{2 \max }$. Heart rate (HR) was recorded during the training sessions by a HR monitor (S610i, Polar Electro, Kempele, Finland).

\section{Rating of Perceived Exertion}

The Borg 6-20 scale (Borg 1982) was selected to rate the perceived intensity of exertion. A verbal-anchored scale was shown to the subjects, after completing of FIT45-15 and after of each intermittent training session, respectively. Each subject was previously familiarized on the use of Borg 6-20 scale, including anchoring procedures. 


\section{Statistical Analyses}

Descriptive statistics (mean $\pm \mathrm{SD}$ ) for the outcome measures were calculated. The normality of the distribution of the demographic (age, body mass, stature and weekly training volume), FIT 45-15 (distance, MAV, HR, $\left.\dot{V} \mathrm{O}_{2 \max }, \mathrm{RER}\right)$ and training session $\left(\dot{V} \mathrm{O}_{2}, \mathrm{HR}, \mathrm{t} 90 \% \dot{\mathrm{V}} \mathrm{O}_{2 \max }\right.$, and RPE) variables were checked using graphical methods and the Kolmogorov-Smirnov test. Since all variables were normally distributed, to determine differences between 30-30 Track, 30-30 Treadmill, and 30-30 $+15 \%$ Treadmill we calculated ordinary one-way analysis of variance and applied Tukey's multiple comparisons test. To determine the difference in peak $\dot{V} \mathrm{O}_{2}$ reached during the 15 bouts of each training sessions we calculated a 2-way analysis of variance and applied the Tukey's multiple comparisons test. The level of significance was set at $\mathrm{P}<0.05$. Statistical analysis was performed using Prism GraphPad (Version 6.0 for Mac OS X, GraphPad Software, Inc., San Diego CA).

\section{Results}

Table 1 presents the mean values of the different physiological parameters measured during the fitness intermittent test 45-15.

\footnotetext{
*** Table 1 about here $* * *$
}

Figure 1 shows the results of the mean values of $\dot{V} \mathrm{O}_{2}$ during the entire training sessions of 3030 Track, 30-30 Treadmill, and 30-30+15\% Treadmill. We observed significant differences between 30-30 Track and 30-30 Treadmill $\left(53.1 \pm 5.4 \mathrm{ml} \cdot \mathrm{kg}^{-1} \cdot \mathrm{min}^{-1} \mathrm{vs} 49.8 \pm 6.7 \mathrm{ml} \cdot \mathrm{kg}^{-1} \cdot \mathrm{min}^{-}\right.$ $\left.{ }^{1},-6.3 \%, \mathrm{P}=0.012\right)$, and 30-30 Track and 30-30+15\% Treadmill $\left(49.9 \pm 6.7 \mathrm{ml} \cdot \mathrm{kg}^{-1} \cdot \mathrm{min}^{-1} \mathrm{vs}\right.$ $\left.53.7 \pm 7.1 \mathrm{ml} \cdot \mathrm{kg}^{-1} \cdot \mathrm{min}^{-1},+7.6 \%, \mathrm{P}=0.016\right)$. No significant difference was observed for HR between 30-30 Track and 30-30 Treadmill sessions (194 \pm 9 bpm vs $192 \pm 8$ bpm, $-1.1 \%, P=$ 
0.892), and between 30-30 Track and 30-30+15\% Treadmill sessions (192 \pm 8 bpm vs $196 \pm 7$ bpm, $+2.0, \mathrm{P}=0.345)$. No significant difference was observed for RER between 30-30 Track and 30-30 Treadmill sessions $(1.30 \pm 0.08$ vs $1.28 \pm 0.7,-1.6 \%, \mathrm{P}=0.746)$, and between 30 30 Track and $30-30+15 \%$ Treadmill sessions $(1.30 \pm 0.08$ vs $1.31 \pm 7,+0.7 \%, \mathrm{P}=0.973)$. Mean oxygen uptake values during 30-30 on track exercise were significantly correlated with mean oxygen uptake values during 30-30 treadmill exercise $(r=0.53 \mathrm{P}=0.049)$ and during $30-30+15 \%$ treadmill exercise $(r=0.56, P=0.047)$.

$* * *$ Figure 1 about here $* * *$

Figure 2 shows the results of the time spent above $t 90 \% \dot{V} \mathrm{O}_{2 \max }$ measured during 30-30 Track, 30-30 Treadmill and 30-30 + 15\% Treadmill sessions. We observed that the time spent at $t 90 \% \dot{V} \mathrm{O}_{2 \max }$ during $30-30$ Treadmill session was significantly lower compared to the time spent at $t 90 \% \dot{V} \mathrm{O}_{2 \max }$ during $30-30$ Track $(8.6 \pm 11.5 \%$ vs $38.7 \pm 32.5 \%,-77.8 \%, \mathrm{P}=0.008)$. Moreover, time spent at $t 90 \% \dot{V} \mathrm{O}_{2 \max }$ during $30-30$ Treadmill was significantly lower compared to the time spent at $t 90 \% \dot{V} \mathrm{O}_{2 \max }$ during $30-30+15 \%$ Treadmill $(8.6 \pm 11.5 \%$ vs $38.8 \pm 2.3 \%,-77.9 \% \mathrm{P}=0.017)$. No statistical significant difference in $t 90 \% \dot{V} \mathrm{O}_{2 \max }$ between 30-30 Track and 30-30 Treadmill $+15 \%$ were detected $(38.7 \pm 32.5 \%$ vs $39.9 \pm 23,+3.1 \%, \mathrm{P}$ $=0.998$. Regarding $t 90 \% \dot{V} \mathrm{O}_{2 \max }$, no significant correlation between $30-30$ on track and 30 30 treadmill exercise and $30-30+15 \%$ treadmill exercise was observed.

$* * *$ Figure 2 about here***

Figure 3, shows the changes in $\dot{V} \mathrm{O}_{2}$ during the 15 repetitions between 30-30 Track and 30-30 Treadmill (Figure 3A) and between 30-30 Track and 30-30 + 15\% Treadmill (Figure 3B). The 
values of $\dot{V} \mathrm{O}_{2}$ reached during the 15 repetitions were significantly higher $(\mathrm{P}<0.05)$ during 30-30 Track compared to 30-30 Treadmill, whereas there was no significant difference between 30-30 Track and 30-30 Treadmill $+15 \%$.

$* * *$ Figure 3 about here***

Figure 4 shows the results of the RPE measured after 30-30 Track, 30-30 Treadmill and 30-30 $+15 \%$ Treadmill. RPE was significantly lower during 30-30 Treadmill than during 30-30 Track $(15.0 \pm 1.4$ vs $11.4 \pm 2.4,-24 \%, \mathrm{P}<0.0001)$. Moreover, RPE during 30-30 Treadmill was significantly lower than RPE during $30-30+15 \%$ Treadmill $(11.4 \pm 1.4$ vs $16.5 \pm 1.7$, $31 \%, \mathrm{P}<0.0001)$. No statistical significant difference between 30-30 Track and 30-30 Treadmill $+15 \%(15.0 \pm 1.4$ vs $16.5 \pm 1.7,+11.0 \%, \mathrm{P}<0.105)$ were detected

$* * * *$ Figure 4 about here $* * * *$

\section{Discussion}

To our knowledge, this was the first study that compares the physiological responses during an HIT running exercise performed outdoor on an athletic track versus on a motorized treadmill at $1 \%$ grade. The physiological response and the perceived exertion were lower during the 30-30 performed on treadmill than the 30-30 performed outdoor on track, while the running velocity was similar. In addition, we found that increasing the velocity by $15 \%$ during the treadmill exercise mimic the cardiovascular responses of the exercise performed in outdoor conditions. 
This of interest for coaches and athletes to transfer of the information gained in the laboratory to the outdoor environment. The motorized treadmill is commonly used to impose exercise stress. Generally, runners train on treadmill because all aspects of the training sessions can be controlled such as i) speed; ii) inclination; iii) warm-up and cool down periods, and is very useful during winter periods for perform a workout in stable conditions. However, unlike outdoor running there is no air resistance during treadmill training sessions. In order to compensate the lack of air resistance, some researchers have used the slight inclinations of the treadmill including 1.0\% (Heck et al. 1985; Jones and Doust 1996) and 2\% (Tegtbur et al. 1993). Other researches have not made any attempt to account the effect of air resistance (Noakes et al. 1990; Weltman et al. 1990) or else made no reference to the matter (Hale et al. 1988). On the other hand, Jones and Doust (1996) were the first to demonstrate that the oxygen cost of running on level outdoors was greater than when running on the level on treadmill. Moreover, they found that a $1 \%$ treadmill grade reflected most accurately the oxygen cost of running outdoors and the oxygen cost at this grade was not significantly different to the oxygen cost of outdoor running for velocities between 2.92 and $5.0 \mathrm{~m} \cdot \mathrm{s}^{-1}$. In particular, the subjects were required to run for 6 minutes at each of six different velocities $\left(2.92,3.33,3.75,4.17,4.58\right.$ and $\left.5.0 \mathrm{~m} \cdot \mathrm{s}^{-1}\right)$ with 6 min recovery between runs both on a treadmill and both outdoors. These assumptions are valid if the velocity during treadmill running is kept constant. Indeed, Van Ingen Schenau (1980) proposed that the mechanics of over ground and treadmill locomotion were similar, but this is not the case for intermittent exercise modalities in which the subject have to accelerate and decelerate continuously. For the same modality of intermittent running performed at MAV, we found that the $\dot{V} \mathrm{O}_{2}$, the time above $90 \% \dot{V} \mathrm{O}_{2 \max }$, and RPE were significantly lower if it was performed on treadmill at $1 \%$ grade than outdoor. A possible explanation of the lower physiological and psychological stress during 30-30 treadmill running could be explained in part by the return of the elastic 
energy from the treadmill at foot contact, with the runner that would impart energy to the belt at toe-off due to the propulsive forces to the foot (Winter 1978). It should also be mentioned that the type of treadmill could influence the biomechanical aspects of running. Nigg et al. (1995), reported that treadmills must have a strong enough driving mechanism that allows to minimize the energy transfer between the subject and the treadmill belt. Furthermore, the sense of balance can be influenced by design factors such as running surface size, height of the treadmill, and a railing for support. We could speculate that larger, more expensive treadmills, typically designed for research and high performance testing as the one used in the present experiment, fulfils these requirements to a greater extent than smaller and less expensive treadmills, typically designed for physical fitness-related situations.

Based on current findings, we wanted to find proper adjustments of 30-30 treadmill training session in order to be physiologically similar to the outdoor conditions. As $\dot{V} \mathrm{O}_{2 \max }$ is considered an important physiological determinant for middle, long distance and team sport performance (Helgerud et al. 2001; Midgley et al. 2006) effective training methods to enhance $\dot{V} \mathrm{O}_{2 \max }$ also in treadmill training sessions have to be determined. To match the intensity of both HIT outdoor and treadmill running exercises, we found that it was required to increase the MAV by $15 \%$ the running velocity for treadmill exercise. By doing this, the $\dot{V} \mathrm{O}_{2}$, $\mathrm{t} 90 \% \dot{V} \mathrm{O}_{2 \max }$, and $\mathrm{HR}$ and $\mathrm{RPE}$ responses were not different during the two training modalities, allowing subjects to train on treadmill with the same physiological strains than in outdoor conditions. This finding suggests that $30-30+15 \%$ Treadmill provides a relevant solution to the problem encountered transferring the 30-30 intermittent running at MAV from outdoor to treadmill conditions. 
In conclusion, the present study demonstrates a $15-\mathrm{min} 30 \mathrm{~s}-30$ s HIT running exercise on treadmill reduces by $6.3 \%$ the mean oxygen uptake compared to the same exercise performed outdoor. An increase in $15 \%$ of running velocity during an HIT training session performed on treadmill at the MAV appears to be a optimal solution to reach the same physiological response than during the same training session performed in outdoor condition. However, future researches need to find adequate velocity adjustment for a large range of running velocities. Moreover, it is not known if an increase of $15 \%$ of the running velocity for welltrained runners who have a greater MAV than our subjects, would still be validated. Athletes need to be careful when they perform a HIT running session on motorized treadmill because the physiological responses are lower compared to the same session performed in outdoor conditions.

\section{Declaration of interest statement}

The authors have no conflicts of interest associated with this manuscript

\section{Acknowledgments}

The authors would like to thank all the students for their voluntary participation in the study and availability for the completion of the all-experimental procedures. 


\section{References}

Assadi, H., and Lepers, R. 2012. Comparison of the 45s-15s Intermittent Running Field Test and the Continuous Treadmill Test. Int. J. Sports. Physiol. Perform. 7(3): 277-284. PMID: 22832116.

Åstrand, I., Astrand, P.O., Christensen, E.H., Hedman, R. 1960. Intermittent muscular work. Acta. Physiol. Scand. 25(48): 448-453. doi: 10.1111/j.1748-1716.1960.tb01879.x. PMID: 13794890.

Billat, V.L., Slawinski, J., Bocquet, V., Demarle, A., Lafitte, L., Chassaing, P., Koralsztein, J.P. 2000. Intermittent runs at the velocity associated with maximal oxygen uptake enables subjects to remain at maximal oxygen uptake for a longer time than intense but submaximal runs. Eur. J. Appl. Physiol. 81(3): 188-196. doi: 10.1007/s004210050029. PMID: 10638376.

Borg, G.A. 1982. Psychophysical bases of perceived exertion. Med. Sci. Sports. Exerc. 14(5): 377-381. PMID: 7154893.

Buchheit, M., and Laursen, P.B. 2013a. High-intensity interval training, solutions to the programming puzzle: Part I: cardiopulmonary emphasis. Sports. Med. 43(5): 313-338. doi: 10.1007/s40279-013-0029-x. PMID: 23539308.

Buchheit, M., and Laursen, P.B. 2013b. High-intensity interval training, solutions to the programming puzzle. Part II: anaerobic energy, neuromuscular load and practical 
applications. Sports. Med. 43(10): 927-54. doi: 10.1007/s40279-013-0066-5. PMID: 23832851.

Burke, J., Thayer, R., Belcamino, M. 1994. Comparison of effects of two interval-training programmes on lactate and ventilatory thresholds. Br. J. Sports. Med. 28(1): 18-21. PMID: 8044486.

Daniels, J., Scardina, N. 1984. Interval training and performance. Sports. Med. 1(4): 327334. PMID: 6390607.

Demarie, S., Koralsztein, J.P., Billat, V. 2000. Time limit and time at VO2max' during a continuous and an intermittent run. J. Sports. Med. Phys. Fitness. 40(2): 96-102. PMID: 11034428.

Fox, E.L., Bartels, R.L., Billings, C.E., Mathews, D.K., Bason, R., Webb, W.M. 1973. Intensity and distance of interval training programs and changes in aerobic power. Med. Sci. Sports. 5(1): 18-22. PMID: 4721844

Fox, E.L., Bartels, R.L., Billings, C.E., O'Brien, R., Bason, R., Mathews, D.K. 1975. Frequency and duration of interval training programs and changes in aerobic power. J. Appl. Physiol. 38(3): 481-484. PMID: 1150561.

Gorostiaga, E.M., Walter, C.B., Foster, C., Hickson, R.C. 1991. Uniqueness of interval and continuous training at the same maintained exercise intensity. Eur. J. Appl. Physiol. Occup. Physiol. 63(2): 101-117. PMID: 1748098 
Heck, H., Mader, A., Hess, G., Mücke, S., Müller, R., Hollmann, W. 1985. Justification of the 4-mmol/1 lactate threshold. Int. J. Sports. Med. 6(3): 117-130. doi: 10.1055/s-20081025824. PMID: 4030186.

Hale, T., Armstrong, N., Hardman, A., Jakeman, P., Sharp, C. and Winter, E. 1988. Position Statement on the Physiological Assessment of the Elite Competitor. In: Leeds (eds). British Association of Sports Sciences.

Helgerud, J., Engen, L.C., Wisloff, U., Hoff, J. 2001. Aerobic endurance training improves soccer performance. Med. Sci. Sports. Exerc. 33(11): 1925-1931. PMID: 11689745 .

Jones, A.M., and Doust, J.H. 1996. A 1\% treadmill grade most accurately reflects the energetic cost of outdoor running. J. Sports. Sci. 14(4):321-327. doi: 10.1080/02640419608727717. PMID: 8887211.

Karlsson, J., Astrand, P.O., Ekblom, B. 1967. Training of the oxygen transport system in man. J. Appl. Physiol. 22(6): 1061-1065. PMID: 6027052.

Laursen, P.B, and Jenkins, D.G. 2002. The scientific basis for high-intensity interval training: optimising training programmes and maximising performance in highly trained endurance athletes. Sports. Med. 32(1): 53-73. PMID: 11772161. 
McLaughlin, J. E., King, G. A., Howley, E. T., Basset, D. R., Ainsworth, B.E. (2001) Validation of the COSMED K4b2 portable metabolic system. Int. J. Sports. Med. 22(4): 280-284. doi: 10.1055/s-2001-13816. PMID: 11414671.

Midgley, A.W., McNaughton, L.R., Wilkinson, M. 2006. Is there an optimal training intensity for enhancing the maximal oxygen uptake of distance runners? empirical research findings, current opinions, physiological rationale and practical recommendations. Sports. Med. 36(2): 117-132. PMID: 16464121

Millet, G.P., Candau, R., Fattori, P., Bignet, F., Varray, A. 2003a. VO2 responses to different intermittent runs at velocity associated with VO2max. Can. J. Appl. Physiol. 28(3): 410-423. PMID: 12955868.

Millet, G.P., Libicz, S., Borrani, F., Fattori, P., Bignet, F., Candau, R. 2003b. Effects of increased intensity of intermittent training in runners with differing VO2 kinetics. Eur. J. Appl. Physiol. 90(1-2): 50-57. doi: 10.1007/s00421-003-0844-0. PMID: 12811566.

Nigg, B.M., De Boer, R.W., Fisher, V. 1995. A kinematic comparison of overground and treadmill running. Med. Sci. Sports. Exerc. 27(1): 98-105. PMID: 7898346.

Noakes, T.D., Myburgh, K.H., Schall, R. 1990. Peak treadmill running velocity during the VO2 max test predicts running performance. J. Sports. Sci. 8(1): 35-45. doi: 10.1080/02640419008732129. PMID: 2359150. 
Overend, T.J., Paterson, D.H., Cunningham, D.A. 1992. The effect of interval and continuous training on the aerobic parameters. Can. J. Sport. Sci. 17(2):129-134. PMID: 1324106.

Schache, A. G., Blanch, P. D., Rath, D. A., Wrigley, T. V., Starr, R., \& Bennell, K. L. 2001. A comparison of overground and treadmill running for measuring the threedimensional kinematics of the lumbo-pelvichip complex. Clinical Biomechanics, 16(8): 667-680. PMID: 11535348.

Sinclair, J., Richards, J., Taylor, P. J., Edmundson, C. J., Brooks, D., Hobbs, S. J. 2013. Three-dimensional kinematic comparison of treadmill and overground running. Sports, Biomech. 12(3):272-82. doi: 10.1080/14763141.2012.759614. PMID: 24245052.

Tardieu-Berger, M., Thevenet, D., Zouhal, H., Prioux, J. 2004. Effects of active recovery between series on performance during an intermittent exercise model in young endurance athletes. Eur. J. Appl. Physiol. 93(1-2): 145-152. doi: 10.1007/s00421-004-1189-z. PMID: 15549368.

Thevenet, D., Tardieu-Berger, M., Berthoin, S., Prioux, J. 2007. Influence of recovery mode (passive vs. active) on time spent at maximal oxygen uptake during an intermittent session in young and endurance-trained athletes. Eur. J. Appl. Physiol. 99(2): 133-142.

Thevenet, D., Tardieu-Berger, M., Zouhal, H., Jacob, C., Abderrahman, B.A., Prioux, J. 2007. Influence of exercise intensity on time spent at high percentage of maximal oxygen 
uptake during an intermittent session in young endurance-trained athletes. Eur. J. Appl. Physiol. 102(1): 19-26.

Tegtbur, U., Busse, M.W., Braumann, K.M. 1993. Estimation of an individual equilibrium between lactate production and catabolism during exercise. Med. Sci. Sports. Exerc. 25(5): $620-7$.

Weltman, A., Snead, D., Stein, P., Seip, R., Schurrer, R., Rutt, R., Weltman, J. 1990. Reliability and validity of a continuous incremental treadmill protocol for the determination of lactate threshold, fixed blood lactate concentrations, and VO2max. Int. J. Sports. Med. 11(1): 26-32.

Winter, D.A. Calculation and interpretation of mechanical energy of movement. In: R. S. Hutton (Ed.). Exerc. Sport. Sci. Rev. 6: 182-201, 1978. 


\section{TABLES}

Table 1. Physiological parameters measured during the fitness intermittent test 45-15.

\begin{tabular}{|c|c|c|c|c|c|}
\hline $\mathbf{N}$ & $\begin{array}{c}\text { Distance } \\
\text { (m) }\end{array}$ & $\begin{array}{l}\text { MAV } \\
\left(\mathbf{k m} \cdot \mathbf{h}^{-1}\right)\end{array}$ & $\begin{array}{c}\text { HR } \\
\left(\mathrm{b} \cdot \mathrm{min}^{-1}\right)\end{array}$ & $\begin{array}{c}\dot{V} \mathbf{O}_{2 \max } \\
\left(\mathrm{ml} \cdot \mathrm{kg} \cdot \mathrm{min}^{-1}\right)\end{array}$ & RER \\
\hline 15 & $155 \pm 8$ & $18.6 \pm 1$ & $199 \pm 4$ & $53.0 \pm 6$ & $1.3 \pm 0.1$ \\
\hline
\end{tabular}

Legend. MAV: Maximal Aerobic Velocity; HR: Heart Rate; $\dot{V} \mathrm{O}_{2 \max }$ : Maximal Oxygen Consumption; RER : Respiratory Exchange Ratio. 


\section{FIGURE CAPTIONS}

Figure 1. Mean oxygen uptake during 30-30 on Track, 30-30 treadmill and 30-30 +15\% treadmill exercises $(* \mathrm{P}<0.05)$.

Figure 2. Time spent at $t 90 \%$ for $30-30$ Track, $30-30$ Treadmill, and $30-30+15 \%$ Treadmill exercises $(* \mathrm{P}<0.05 ; * * \mathrm{P}<0.001)$.

Figure 3. Changes in oxygen uptake $\dot{V} \mathrm{O}_{2}$ during the 15 bouts for $30-30$ Track versus $30-30$ Treadmill (Panel A) and 30-30 Track versus 30-30 + 15\% Treadmill (Panel B), $(* \mathrm{P}<0.05)$.

Figure 4. Rate of perceived exertion (RPE) after the 30-30 Track, 30-30 Treadmill and 30-30 $+15 \%$ Treadmill exercises $(* * * * \mathrm{P}<0.0001)$. 


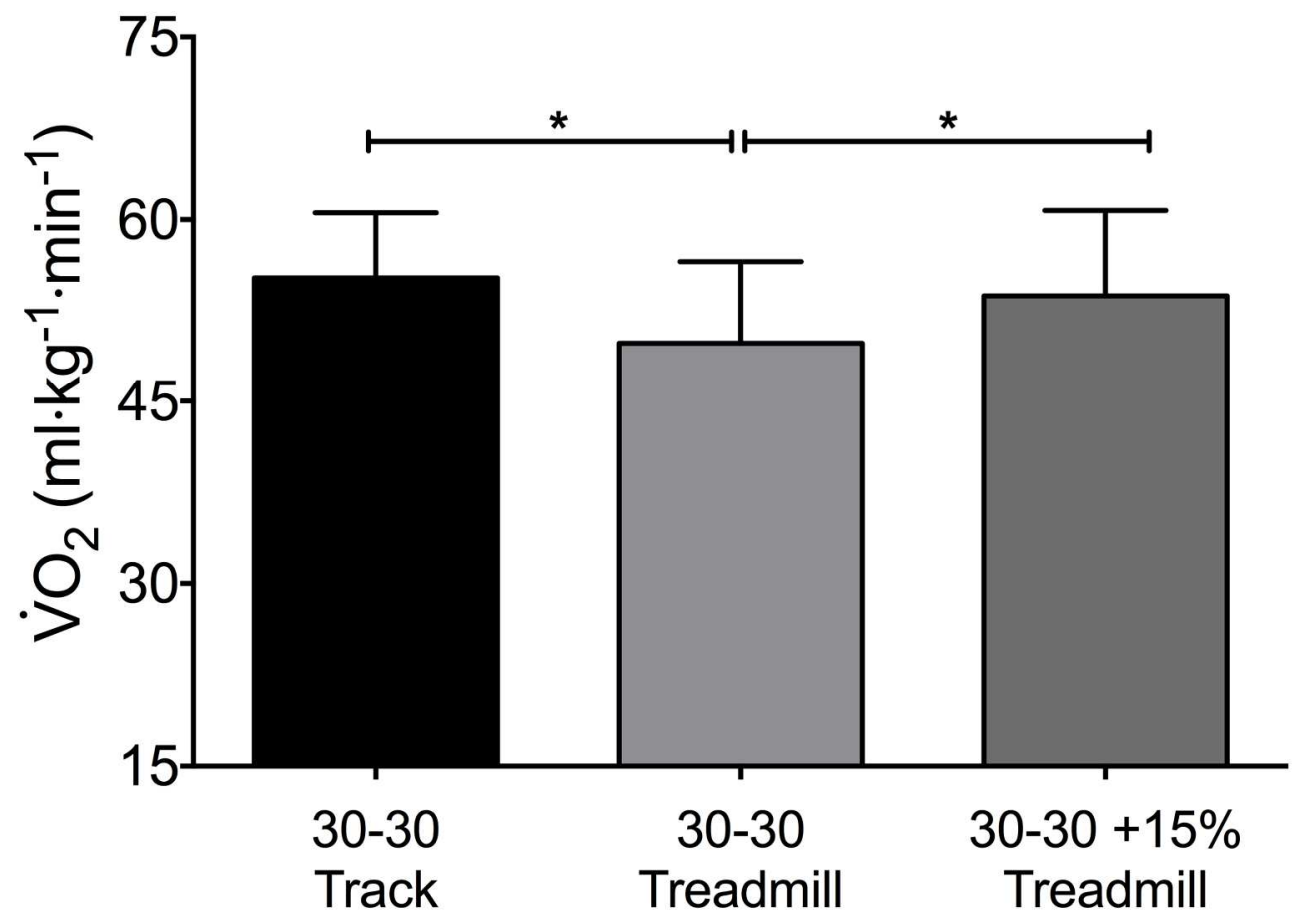

Mean oxygen uptake during $30-30$ on Track, $30-30$ treadmill and $30-30+15 \%$ treadmill exercises (* $\mathrm{P}<$ $0.05)$.

$196 \times 145 \mathrm{~mm}(300 \times 300 \mathrm{DPI})$ 


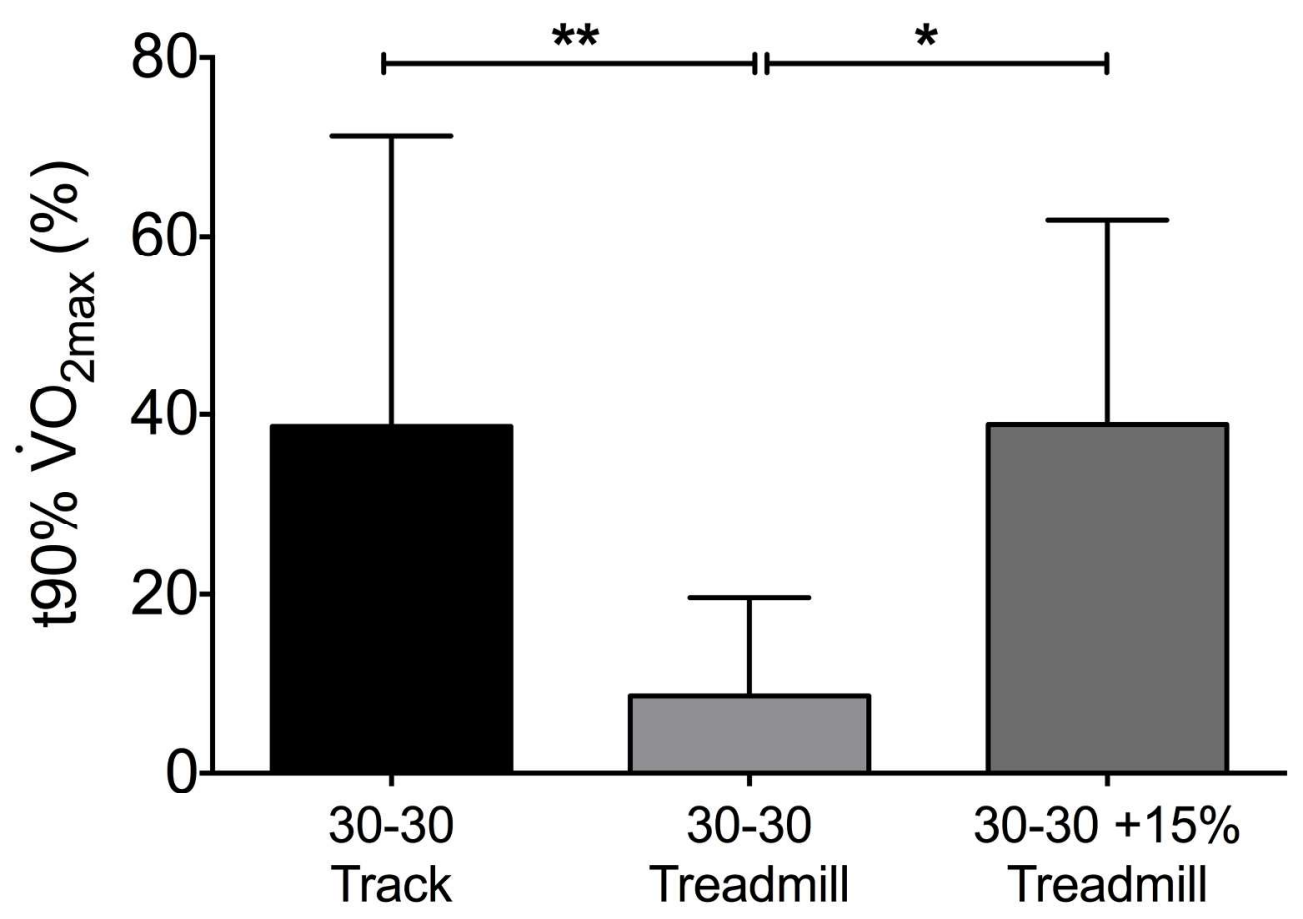

Time spent at 90\% for 30-30 Track, 30-30 Treadmill, and 30-30 + 15\% Treadmill exercises $(* \mathrm{P}<0.05$; $* * \mathrm{P}<0.001)$.

$200 \times 145 \mathrm{~mm}(300 \times 300$ DPI $)$ 

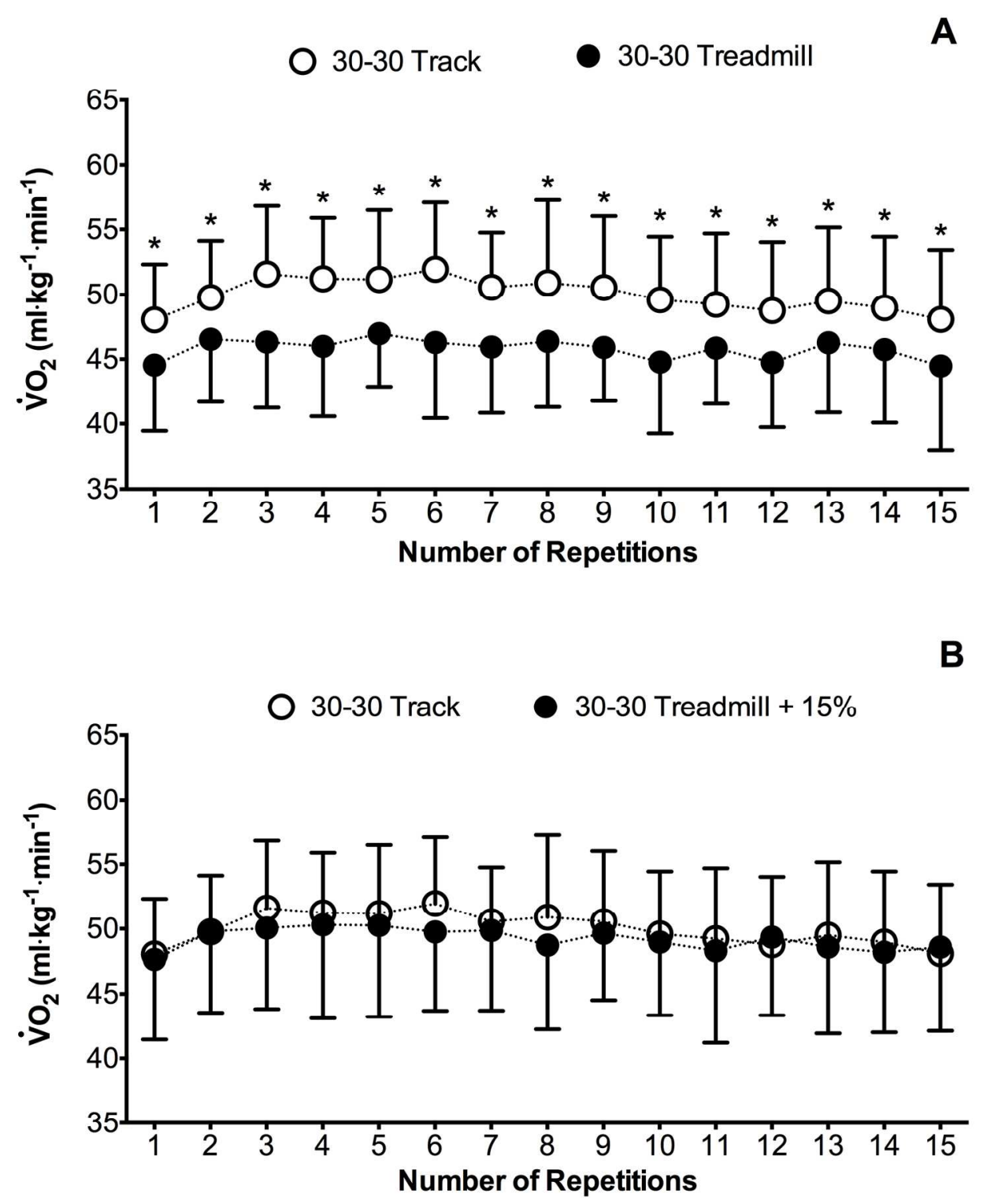

Changes in oxygen uptake $\mathrm{O} 2$ during the 15 bouts for 30-30 Track versus 30-30 Treadmill (Panel A) and 3030 Track versus $30-30+15 \%$ Treadmill (Panel $\mathrm{B}),(* \mathrm{P}<0.05)$.

$166 \times 202 \mathrm{~mm}(300 \times 300$ DPI $)$ 


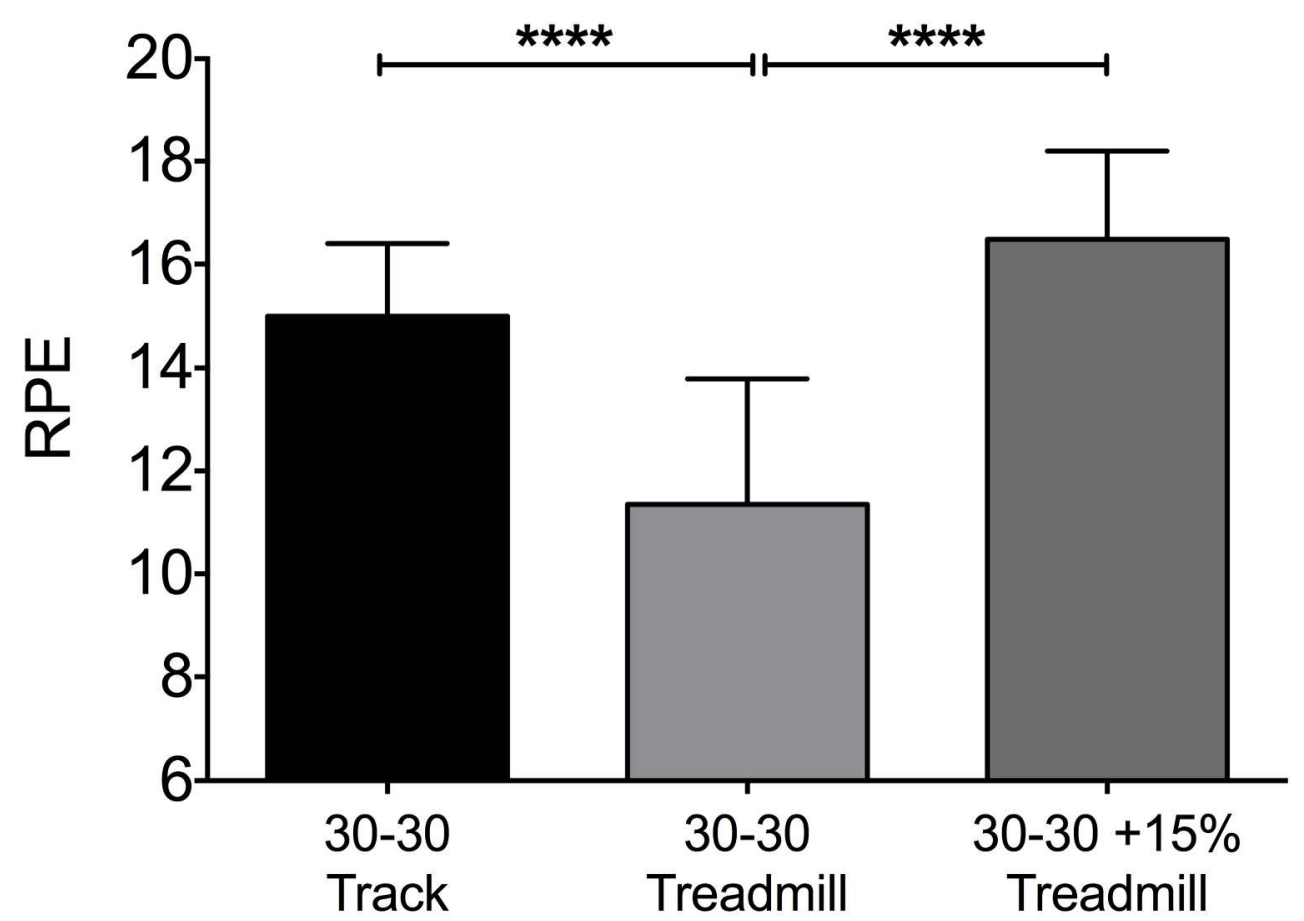

Rate of perceived exertion (RPE) after the 30-30 Track, 30-30 Treadmill and 30-30 + 15\% Treadmill exercises $(* * * * \mathrm{P}<0.0001)$.

$198 \times 145 \mathrm{~mm}(300 \times 300 \mathrm{DPI})$ 